\title{
The Activity of Immune Checkpoint Inhibition in KRAS Mutated Non-small Cell Lung Cancer: A Single Centre Experience
}

\author{
JAVIER TORRALVO $^{1}$, ALEX FRIEDLAENDER $^{1}$, VERANE ACHARD $^{2}$ and ALFREDO ADDEO ${ }^{1}$ \\ ${ }^{1}$ Oncology Department, Geneva University Hospital, Geneva, Switzerland; \\ ${ }^{2}$ Department of Radiation Oncology, Geneva University Hospital, Geneva, Switzerland
}

\begin{abstract}
Background/Aim: KRAS mutation is the most frequent molecular alteration found in advanced non-small cell lung cancer (NSCLC). It is associated with a poor prognosis without available targeted therapy. Treatment options for NSCLC have been recently enriched by the development of immune checkpoint inhibitors (ICIs), and data about their efficacy in patients with KRAS-mutant NSCLC are discordant. This study assessed the routine efficacy of ICIs in advanced KRAS-mutant NSCLC. Patients and Methods: All stage IV NSCLC patients treated in our institution from January 2016 to December 2017 with immunotherapy were included in our analysis. We collected the status of KRAS and other mutations, as well as the type of ICI administered. We assessed four clinical outcomes: i) disease control rate (DCR), ii) partial response (PR), iii) progression-free survival (PFS) and iv) overall survival (OS). Results: A total of 45 patients were initially identified but 7 were excluded due to insufficient clinical data, so 38 were included in the end. In the KRAS wildtype cohort, the DCR was $59 \%$ with $49 \%$ PR, while the PFS was 8.4 months and OS 16.8 months. Among KRAS mutated patients, results were more favourable, the DCR was $81 \%$, with 62\% PR. PFS was 13.6 months and OS was 18.5 months. The median follow-up was 24 months (17 to 34 months) and 7 patients were still on treatment at the time of analysis. Conclusion: Our data suggest that KRAS mutation is predictive of a superior response to immunotherapy. Furthermore, the lack of response of STK11 and KRAS co-mutated NSCLC patients to ICIs, is indeed negated by an additional TP53 mutation.
\end{abstract}

This article is freely accessible online.

Correspondence to: Alfredo Addeo, Oncology Department, Geneva University Hospital, 4 rue Gabrielle Perret-Gentil, 1205, Geneva, Switzerland. Tel: +41 3729862, Fax: +41 3723375, e-mail: alfredo.addeo@hcuge.ch

Key Words: Non-small cell lung cancer, KRAS, immunotherapy.
Representing $11.6 \%$ of all cancers, lung cancer is the most commonly diagnosed malignancy, as well as the leading cause of cancer-related mortality worldwide. It is responsible for $18.4 \%$ of all cancer-related deaths (1). It is divided into two main categories: i) small cell lung cancer and ii) non-small cell lung cancer (NSCLC). Accounting for $85 \%$ of all lung cancers, NSCLC encompasses two main histotypes: i) adenocarcinoma (ADC) (60\%) and ii) squamous cell carcinoma (SqCC) (35\%) (2), each with separate mutational profiles. Historically, lung cancer was known to be a smoker's disease, but today, $15 \%$ of NSCLC cases in men and $53 \%$ in women occur in people that have never smoked (3).

In the last decade, the treatment landscape has evolved thanks to the introduction of immune checkpoint inhibitors (ICIs), mainly targeting: i) programmed death-1 (PD-1), ii) programmed death ligand-1 (PD-L1) and iii) cytotoxic Tlymphocyte-associated antigen-4 (CTLA-4). ICIs have changed the treatment algorithm for metastatic NSCLC patients, and have improved their prognosis. PD-L1, an immune checkpoint protein found in tumour cells or tumourinfiltrating immune cells, binds PD-1 receptors on activated T-cells, inducing tumour immune escape by down-regulating anti-tumoral T-cell function. By inhibiting this pathway, T-cell activity is restored, inducing immune responses towards cancer cells (4-6). Currently, PD-1 blockade shows a substantial improvement in the overall survival (OS) of NSCLC patients and a subset of them shows long lasting responses. However, response rates still remain low, with the majority of patients not obtaining any benefit from ICI, and 5-year survival rates between 15-29\% (7-9).

Therapeutic options for ADC have also increased in recent years thanks to the identification and treatment of oncogenic mutations, known as driver mutations. These are more frequent among non-smokers and younger patients (10). In spite of this progress, the Kirsten Rat Sarcoma (KRAS) mutation, the most commonly detected oncogenic driver, has yet to be successfully targeted. These mutations are found mainly in ADC and are strongly correlated to smoking (11). 
Table I. Patient and tumour characteristics.

\begin{tabular}{|c|c|c|c|c|c|c|c|}
\hline Patient & Age & Gender & Histology & PY & KRAS mutation & Other mutations & $\mathrm{ICI} /$ line \\
\hline 1 & 68 & Male & $\mathrm{ADC}$ & 60 & G12V & $\begin{array}{l}\text { STK11 } \\
\text { TP53 }\end{array}$ & $\mathrm{Nivo} / 2$ \\
\hline 2 & 51 & Female & $\mathrm{ADC}$ & 5 & No & EGFR exon 20 & $\mathrm{Nivo} / 2$ \\
\hline 3 & 62 & Male & $\mathrm{ADC}$ & 60 & G12C & No & $\mathrm{Pem} / 2$ \\
\hline 4 & 71 & Female & $\mathrm{ADC}$ & 0 & No & TP53 & $\mathrm{Nivo} / 2$ \\
\hline 5 & 60 & Male & $\mathrm{SqCC}$ & 70 & No & TP53 & $\mathrm{Nivo} / 2$ \\
\hline 6 & 69 & Male & $\mathrm{ADC}$ & 60 & G13C & No & $\mathrm{Pem} / 2$ \\
\hline 7 & 60 & Male & $\mathrm{ADC}$ & 40 & No & TP53 & $\mathrm{Nivo} / 2$ \\
\hline 8 & 58 & Female & $\mathrm{ADC}$ & 40 & No & $\begin{array}{c}\text { PIK3CA } \\
\text { TP53 }\end{array}$ & $\mathrm{Pem} / 2$ \\
\hline 9 & 61 & Female & $\mathrm{ADC}$ & 0 & No & EGFR exon 20 & Ate $/ 3$ \\
\hline 10 & 70 & Female & $\mathrm{ADC}$ & 10 & No & $\begin{array}{c}\text { EGFR exon } 21 \\
\text { TP53 }\end{array}$ & Ate $/ 5$ \\
\hline 11 & 55 & Female & $\mathrm{ADC}$ & 30 & G12V & No & $\mathrm{Nivo} / 2$ \\
\hline 12 & 68 & Male & $\mathrm{ADC}$ & 40 & G12A & No & $\mathrm{Pem} / 2$ \\
\hline 13 & 47 & Female & $\mathrm{ADC}$ & 0 & G61H & EGFR exon 19 & $\mathrm{Pem} / 2$ \\
\hline 14 & 69 & Male & $\mathrm{ADC}$ & 60 & G13C & No & $\mathrm{Nivo} / 2$ \\
\hline 15 & 51 & Male & $\mathrm{ADC}$ & 25 & $\mathrm{G} 12 \mathrm{C}$ & No & $\mathrm{Nivo} / 2$ \\
\hline 16 & 64 & Female & $\mathrm{ADC}$ & 60 & G12V & No & $\mathrm{Nivo} / 2$ \\
\hline 17 & 74 & Male & $\mathrm{ADC}$ & 25 & $\mathrm{G} 12 \mathrm{C}$ & TP53 & $\mathrm{Nivo} / 2$ \\
\hline 18 & 61 & Male & $\mathrm{ADC}$ & 60 & G61H & No & $\mathrm{Pem} / 2$ \\
\hline 19 & 47 & Male & $\mathrm{ADC}$ & 40 & No & TP53 & $\mathrm{Nivo} / 2$ \\
\hline 20 & 68 & Female & $\mathrm{ADC}$ & 25 & No & CDKN2A & $\mathrm{Pem} / 2$ \\
\hline 21 & 71 & Male & $\mathrm{ADC}$ & 30 & No & No & $\mathrm{Nivo} / 2$ \\
\hline 22 & 67 & Male & $\mathrm{ADC}$ & 42 & No & TP53 & $\mathrm{Nivo} / 2$ \\
\hline 23 & 62 & Female & $\mathrm{ADC}$ & 0 & G12D & $\begin{array}{l}\text { PTEN } \\
\text { TP53 }\end{array}$ & $\mathrm{Nivo} / 2$ \\
\hline 24 & 73 & Female & $\mathrm{ADC}$ & 20 & No & No & $\mathrm{Nivo} / 2$ \\
\hline 25 & 71 & Male & $\mathrm{ADC}$ & 75 & No & $\begin{array}{c}\text { BRAF V600E } \\
\text { TP53 } \\
\text { HRAS }\end{array}$ & $\mathrm{Nivo} / 2$ \\
\hline 26 & 83 & Female & $\mathrm{ADC}$ & 40 & $\mathrm{G} 12 \mathrm{C}$ & No & $\mathrm{Nivo} / 2$ \\
\hline 27 & 44 & Female & $\mathrm{ADC}$ & 30 & G12A & No & $\mathrm{Nivo} / 2$ \\
\hline 28 & 53 & Male & $\mathrm{ADC}$ & 16 & No & EGFR exon 20 & $\mathrm{Pem} / 2$ \\
\hline 29 & 56 & Male & $\mathrm{ADC}$ & 50 & $\mathrm{G} 12 \mathrm{C}$ & No & $\mathrm{Nivo} / 2$ \\
\hline 30 & 78 & Male & $\mathrm{ADC}$ & 120 & $\mathrm{G} 12 \mathrm{C}$ & No & $\mathrm{Nivo} / 2$ \\
\hline 31 & 73 & Female & $\mathrm{ADC}$ & 50 & G12V & No & $\mathrm{Nivo} / 2$ \\
\hline 32 & 54 & Female & $\mathrm{ADC}$ & 35 & No & TP53, STK11, APC, CDKN2A & $\mathrm{Nivo} / 2$ \\
\hline 33 & 72 & Male & $\mathrm{ADC}$ & 50 & $\mathrm{G} 12 \mathrm{C}$ & No & $\mathrm{Pem} / 2$ \\
\hline 34 & 43 & Female & $\mathrm{SqCC}$ & 60 & No & $\begin{array}{l}\text { CDKN2A } \\
\text { TP53 }\end{array}$ & $\mathrm{Nivo} / 2$ \\
\hline 35 & 44 & Male & $\mathrm{ADC}$ & 45 & G12V & No & $\mathrm{Nivo} / 2$ \\
\hline 36 & 59 & Male & $\mathrm{SqCC}$ & 70 & No & TP53 & $\mathrm{Nivo} / 2$ \\
\hline 37 & 77 & Female & ADC & 60 & $\mathrm{G} 12 \mathrm{C}$ & TP53 & $\mathrm{Nivo} / 2$ \\
\hline 38 & 70 & Female & $\mathrm{ADC}$ & 20 & G12C & No & $\mathrm{Nivo} / 2$ \\
\hline
\end{tabular}

ADC: Adenocarcinoma; SqCC: squamous cell carcinoma; PY: pack years; ICI: immune-checkpoint inhibitor; Nivo: nivolumab; Pem: pembrolizumab; Ate: atezolizumab.

KRAS has been mainly identified as predictive of poor response to chemotherapy and is generally considered an adverse prognostic factor in advanced NSCLC (12-14). Interestingly, in the rare cases of concomitant epidermal growth factor receptor (EGFR) or anaplastic lymphoma kinase (ALK) mutations, KRAS mutation is not necessarily predictive of poor response to targeted therapy (15).
An exception has been observed in KRAS mutated patients undergoing PD-1 blockade for advanced NSCLC. An unplanned subgroup analysis in "Checkmate 057" (16), has found a possible advantage of ICI in KRAS mutated NSCLC patients. In a recent meta-analysis by Kim et al., ICIs were compared to docetaxel in pre-treated NSCLC patients, with results stratified depending on the KRAS 

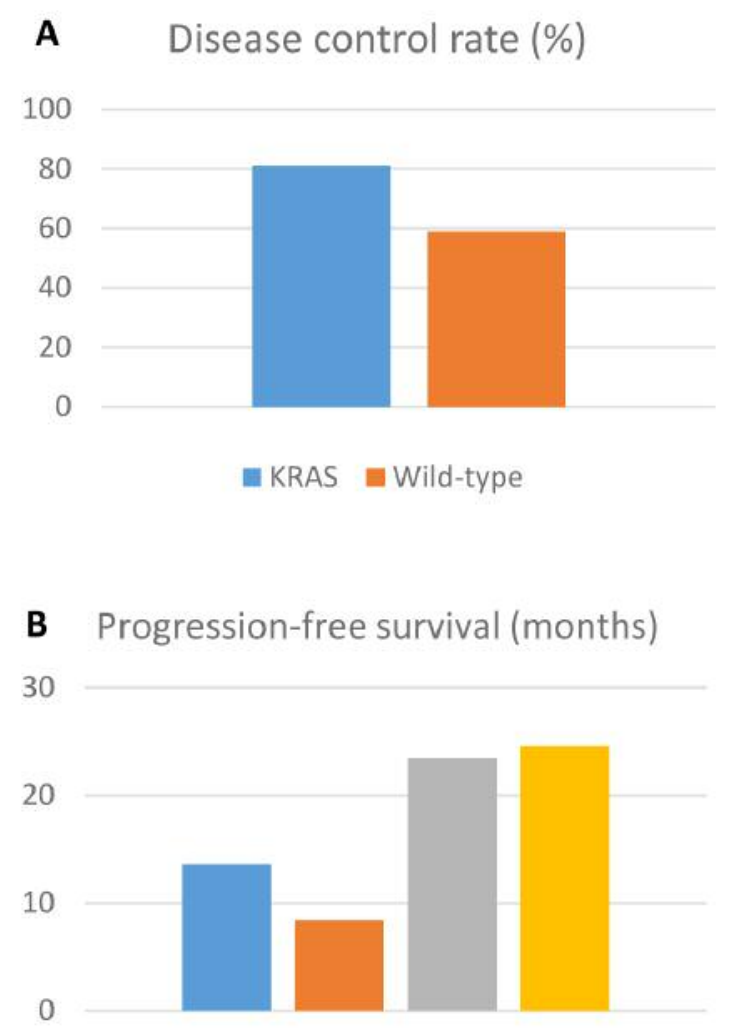

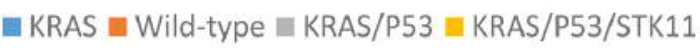

\section{Overall survival (months)}

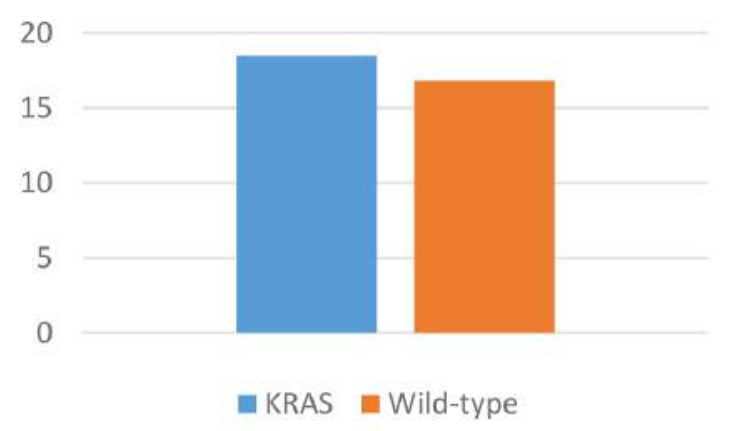

Figure 1. Immune check-point inhibitor activity. A. Disease control rate in KRAS-mutated and wild-type patients. B. Progression-free survival among KRAS mutated patients, wild-type patients, and KRAS patients with concurrent mutations. $C$. Overall survival among KRAS mutated and wild-type patients.

status. Again, KRAS mutated patients derived significant survival benefit from ICIs versus chemotherapy, while the same was not found in wild-type patients (17). Nevertheless, data are lacking to strongly support the predictive value of KRAS mutations. Recent large retrospective analyses did not confirm these findings (18).
There is a biological rationale behind a potential interaction between KRAS mutations and sensitivity to ICI. KRAS mutated in NSCLC represents a heterogeneous group of diseases with distinct molecular patterns. Generally, this group exhibits an increased tumour mutation burden, potentially leading to increased sensitivity to ICI (19). In case of concomitant alterations, such as mutations of tumour suppressors TP53 or STK11, KRAS mutated tumours can be differentiated into distinct phenotypes. For instance, concomitant KRAS with TP53 mutations are associated with enhanced tumour cell proliferation and inflammation (20). In contrast, STK11 mutations may potentiate KRAS-induced signalling and gene-expression without increased proliferation. However, STK11 mutations decrease immune surveillance, possibly by impacting on the NF-kB pathway. STK11 mutations are also associated with decreased tumour infiltrating lymphocytes (TILs), which significantly contribute to the suppression of the immune surveillance response $(20,21)$. The resulting immune-inactive tumour microenvironment could be predictive of poor response to ICI. Thus, KRAS mutations could, depending on concurrent mutations, be predictive of response or resistance to ICI. Herein, given this biological rationale, we will evaluate the predictive role of KRAS and concurrent mutations in ICI in advanced NSCLC. The clinical outcomes analysed are disease control rate (DCR), partial response (PR), progression free survival (PFS) and OS.

\section{Patients and Methods}

We analysed all stage IV lung cancer patients treated in our institution from January 2016 to December 2017 and included patients treated with immunotherapy as first or subsequent lines of treatment, independent of other prior treatments, such as chemotherapy. Patients who never received ICI and SCLC patients were excluded.

For these patients, we collected mutation data from medical and pathology records, such as KRAS or other mutations, including EGFR, ALK, BRAF, phosphatidylinositol-4,5-bisphosphate 3kinase, catalytic subunit alpha (PIK3CA), cyclin-dependent kinase inhibitor 2A (CDKN2A), TP53, STK11. We specified the type of KRAS mutation, for an exploratory analysis on the impact of specific mutations on the outcomes we assessed. Data on the type of ICIs administered (pembrolizumab, nivolumab or atezolizumab), duration and line of treatment were collected. Using this dataset, we assessed four clinical outcomes and compared them in patients harbouring KRAS mutations, those with concurrent mutations and wild-type patients: i) disease control rate (DCR), ii) partial response (PR), iii) progression free survival (PFS) and iv) overall survival (OS). We defined our clinical outcomes as follows: i) DCR represents stable disease or response to ICI according to the radiological RECIST 1.1 criteria (22); ii) PR corresponds to a decrease of at least $30 \%$ in the sum of diameters of measurable lesions; iii) PFS is defined as the absence of clinical or radiological progression in patients alive and on ICI treatment; iv) OS represents the time from start of treatment to death. 


\section{Results}

From January 2016 to December 2017, 45 patients were identified but 7 were excluded due to insufficient clinical data. $27(71 \%)$ of the total 38 patients were treated with nivolumab, 9 patients $(24 \%)$ with pembrolizumab and 2 patients $(5 \%)$ with atezolizumab. Twenty-two patients $(58 \%)$ were male and $16(42 \%)$ female. The median age was 63 . Twenty-one patients $(55 \%)$ presented KRAS mutations, of which $4(19 \%)$ had concurrent p53 mutations (one with an additional STK11 mutation, and one more with an EGFR mutation). All KRAS mutated patients had ADC.

Seventeen patients (45\%) were KRAS wild-type, of which $4(24 \%)$ had EGFR mutations, $1(6 \%)$ a BRAF V600E mutation, and $1(6 \%)$ an STK11 mutation. In the KRAS mutated subgroup $57 \%$ were male and $43 \%$ were female, the median age was 61 years and all patients had PS 0-1. All patients received second line immunotherapy except for 2 , one in the third line, one in the fifth line. Fourteen KRAS wild-type patients had ADC, while 3 had SqCC (Table I).

In the entire cohort the disease control rate (DCR) was $71 \%$ with 55\% PR, while PFS was 11.3 months and OS 17.7 months. In the KRAS wild-type subgroup, DCR was $59 \%$ with $49 \% \mathrm{PR}$, while the PFS was 8.4 months and the OS was 16.8 months. In the KRAS mutated subgroup, DCR was $81 \%$, with $62 \%$ PR. PFS was 13.6 months and OS was 18.5 months (Figure 1).

Among KRAS patients, 9 had G12C mutations, 5 had G12V, 2 had G13C, 1 had G12D, 2 had G12A, and 2 had G61H mutations.

An exploratory analysis based on KRAS mutation types or co-mutations was performed. The average PFS for G12C, G13C, G12V, G61H and other mutations was 19.1, 7.8, 9.4, 2.2, and 13.9 months, respectively. PFS for TP53 co-mutated KRAS NSCLC was 23.5 months. The patient with concurrent STK11, KRAS, TP53 mutations had a PFS of 24.6 months and was still on treatment, while the STK11 non-KRAS comutated patient had a PFS of 6.2 months. At the time of analysis 7 patients were still receiving immunotherapy. The median follow-up was 24 months (17 to 34 months).

\section{Discussion}

The prognostic and predictive value of KRAS mutations in NSCLC remains unclear (23). Recently, a trial found that the double mutation TP53/KRAS manifested an expression of PD-L1 and high TILs, and it was associated with a remarkable clinical benefit when PD-1 inhibitors were used compared to patients without these mutations (19). This is compatible with the biological characteristics of our subgroup of KRAS mutated patients, who exhibit a highly active immune microenvironment. On the other hand, concurrent STK11 mutations, present in roughly $20 \%$ of KRAS mutated NSCLC, are associated with a resistance to
ICIs, consistent with the poor immune microenvironment associated with this mutation (24-26).

Moreover, several other trials have shown an association between KRAS mutation and better response to ICI, even independently of PD-L1 expression and TP53 mutations (27). Our findings are in line with these results and show favourable outcomes for these NSCLC, with an improved ORR, PFS and OS in KRAS mutant patients. However, we noted a significantly improved PFS among the TP53/KRAS double mutant patients, which is encouraging as a predictive marker for ICI. The multi-centric retrospective ImmunoTarget trial (28) was designed to determine the sensitivity of NSCLC patients with oncogenic driver mutations to ICIs. Preliminary results have shown inconsistent efficacy among patients with driver mutations, but demonstrated superior results in patients with KRAS, BRAF and MET mutations compared to EGFR, ALK and RET alterations (29). KRAS data from this trial is still awaited. Meanwhile, a recent retrospective trial has evaluated the impact of immunotherapy in 282 NSCLC patients of which 162 were KRAS-mutated. The authors concluded that there was no difference in ORR, PFS or OR among the KRAS mutated or wild-type patients, and that the type of KRAS mutation did not impact survival (18). Nonetheless, given the larger cohort of 252 KRAS patients in the Immunotarget trial, a confirmatory analysis of the type of the impact of the KRAS mutation on the response to immunotherapy would be welcome.

KRAS encompasses a complex and heterogeneous set of mutations. The presence of KRAS mutations in NSCLC patients could be a predictive factor for their response to immunotherapy. Current data suggest concurrent mutations may be most significant in predicting response or resistance to therapy.

In our study, KRAS mutations in NSCLC were predictive of superior response to ICI compared to wild-type patients. Currently, the data is conflicting and larger clinical trials, such as the final results and analyses of the ImmunoTarget trial (28), are needed to clarify this hypothesis and ascertain whether and how KRAS should be part of the treatment algorithm for the selection of ICI patients. Today, the clearest results are a lack of response to ICI in STK11 and KRAS comutant NSCLC patients, though this effect is cancelled by the presence of an additional TP53 mutation. It is worth noting that KRAS mutations may also allow for alternative treatment choices. Recent early clinical data for small molecules targeting KRAS G12C, which is present in $13 \%$ of NSCLC, showed promising activity and will likely significantly alter the treatment landscape for these patients (30).

Furthermore, there must be caution so as to distinguish KRAS-dependent from KRAS-independent tumours, as grouping all together could dilute results as well as the predictive value of these mutations in NSCLC to ICIs. This needs to be analysed in larger cohorts. 
Our study supports the predictive role of KRAS mutations in NSCLC treated by ICIs. Currently, the data are not robust enough to impact therapeutic choices. However, KRAS status and concurrent mutations could be integrated into a greater predictive model to determine which patients are most likely to benefit from, or fail to respond to, ICIs.

\section{Conflicts of Interest}

AA reported receiving grants and personal fees from Boehringer Ingelheim and personal fees from Pfizer, Roche, Merck Sharp \& Dohme, Takeda, and Bristol-Myers Squibb outside the submitted work. FA reported fees from an advisory role for Bristol-Myers Squibb, Astellas, Pfizer and Roche outside the submitted work. TJ and VA reported no conflicts of interest.

\section{Authors' Contributions}

AA, TJ and FA were responsible for the concept of this study. TJ and FA collected data. AA and FA performed the data analysis. AA, $\mathrm{AV}, \mathrm{FA}$ and $\mathrm{TJ}$ wrote and edited this paper.

\section{References}

1 Bray F, Ferlay J, Soerjomataram I, Siegel RL, Torre LA and Jemal A: Global cancer statistics 2018: Globocan estimates of incidence and mortality worldwide for 36 cancers in 185 countries. CA Cancer J Clin 68(6): 394-424, 2018. PMID: 30207593. DOI: $10.3322 / \mathrm{caac} .21492$

2 Howlader N, Noone AM, Krapcho M, Miller D, Bishop K, Kosary CL, Yu M, Ruhl J, Tatalovich Z, Mariotto A, Lewis DR, Chen HS, Feuer EJ and Cronin KA: SEER Cancer Statistics Review, 1975-2014, National Cancer Institute, 2017. Available from: https://seer.cancer.gov/csr/1975_2014/

3 Parkin DM, Bray F, Ferlay $J$ and Pisani P: Global cancer statistics, 2002. CA Cancer J Clin 55(2): 74-108, 2005. PMID: 15761078. DOI: $10.3322 /$ canjclin.55.2.74

4 Chen DS, Irving BA and Hodi FS: Molecular pathways: Nextgeneration immunotherapy - inhibiting programmed deathligand 1 and programmed death-1. Clin Cancer Res 18(24): 6580-6587, 2012. PMID: 23087408. DOI: 10.1158/10780432.CCR-12-1362

5 Chen DS and Mellman I: Oncology meets immunology: The cancer-immunity cycle. Immunity 39(1): 1-10, 2013. PMID: 23890059. DOI: 10.1016/j.immuni.2013.07.012

6 Pardoll DM: The blockade of immune checkpoints in cancer immunotherapy. Nat Rev Cancer 12(4): 252-264, 2012. PMID: 22437870. DOI: $10.1038 / \mathrm{nrc} 3239$

7 Novello S, Milella M, Tiseo M, Banna G, Cortinovis D, Di Maio M, Garassino M, Maione P, Martelli O, Vavala T and Bria E: Maintenance therapy in NSCLC: Why? To whom? Which agent? J Exp Clin Cancer Res 30: 50, 2011. PMID: 21548925. DOI: 10.1186/1756-9966-30-50

8 Garon EB, Hellmann MD, Rizvi NA, Carcereny E, Leighl NB, Ahn MJ, Eder JP, Balmanoukian AS, Aggarwal C, Horn L, Patnaik A, Gubens M, Ramalingam SS, Felip E, Goldman JW, Scalzo C, Jensen E, Kush DA and Hui R: Five-year overall survival for patients with advanced nonsmall-cell lung cancer treated with pembrolizumab: Results from the phase i keynote-
001 study. J Clin Oncol: JCO1900934, 2019. PMID: 31154919. DOI: $10.1200 / \mathrm{JCO} .19 .00934$

9 Gettinger S, Horn L, Jackman D, Spigel D, Antonia S, Hellmann M, Powderly J, Heist R, Sequist LV, Smith DC, Leming P, Geese WJ, Yoon D, Li A and Brahmer J: Five-year follow-up of nivolumab in previously treated advanced non-small-cell lung cancer: Results from the ca209-003 study. J Clin Oncol 36(17): 1675-1684, 2018. PMID: 29570421. DOI: 10.1200/JCO. 2017.77.0412

10 Friedlaender A, Banna G, Malapelle U, Pisapia P and Addeo A: Next generation sequencing and genetic alterations in squamous cell lung carcinoma: Where are we today? Front Oncol 9: 166, 2019. PMID: 30941314. DOI: 10.3389/fonc.2019.00166

11 Dogan S, Shen R, Ang DC, Johnson ML, D'Angelo SP, Paik PK, Brzostowski EB, Riely GJ, Kris MG, Zakowski MF and Ladanyi M: Molecular epidemiology of EGFR and KRAS mutations in 3,026 lung adenocarcinomas: Higher susceptibility of women to smoking-related kras-mutant cancers. Clin Cancer Res 18(22): 6169-6177, 2012. PMID: 23014527. DOI: 10.1158/1078-0432. CCR-11-3265

12 Karachaliou N, Mayo C, Costa C, Magri I, Gimenez-Capitan A, Molina-Vila MA and Rosell R: Kras mutations in lung cancer. Clin Lung Cancer 14(3): 205-214, 2013. PMID: 23122493. DOI: 10.1016/j.cllc.2012.09.007

13 Macerelli M, Caramella C, Faivre L, Besse B, Planchard D, Polo V, Ngo Camus M, Celebic A, Koubi-Pick V, Lacroix L, Pignon JP and Soria JC: Does kras mutational status predict chemoresistance in advanced non-small cell lung cancer (NSCLC)? Lung Cancer 83(3): 383-388, 2014. PMID: 24439569. DOI: 10.1016/j.lungcan.2013.12.013

14 Marabese M, Ganzinelli M, Garassino MC, Shepherd FA, Piva S, Caiola E, Macerelli M, Bettini A, Lauricella C, Floriani I, Farina G, Longo F, Bonomi L, Fabbri MA, Veronese S, Marsoni S, Broggini M and Rulli E: Kras mutations affect prognosis of non-small-cell lung cancer patients treated with first-line platinum containing chemotherapy. Oncotarget 6(32): 3401434022, 2015. PMID: 26416458. DOI: 10.18632/oncotarget.5607

15 Lee T, Lee B, Choi YL, Han J, Ahn MJ and Um SW: Non-small cell lung cancer with concomitant egfr, kras, and alk mutation: Clinicopathologic features of 12 cases. J Pathol Trans1 Med 50(3): 197-203, 2016. PMID: 27086595. DOI: 10.4132/jptm. 2016.03.09

16 Borghaei H, Paz-Ares L, Horn L, Spigel DR, Steins M, Ready NE, Chow LQ, Vokes EE, Felip E, Holgado E, Barlesi F, Kohlhaufl M, Arrieta O, Burgio MA, Fayette J, Lena H, Poddubskaya E, Gerber DE, Gettinger SN, Rudin CM, Rizvi N, Crino L, Blumenschein GR Jr., Antonia SJ, Dorange C, Harbison CT, Graf Finckenstein F and Brahmer JR: Nivolumab versus docetaxel in advanced nonsquamous non-small-cell lung cancer. N Engl J Med 373(17): 1627-1639, 2015. PMID: 26412456. DOI: 10.1056/NEJMoa1507643

17 Kim JH, Kim HS and Kim BJ: Prognostic value of kras mutation in advanced non-small-cell lung cancer treated with immune checkpoint inhibitors: A meta-analysis and review. Oncotarget 8(29): 48248-48252, 2017. PMID: 28525386. DOI: 10.18632/ oncotarget.17594

18 Jeanson A, Tomasini P, Souquet-Bressand M, Brandone N, Boucekine M, Grangeon M, Chaleat S, Khobta N, Milia J, Mhanna L, Greillier L, Biemar J, Nanni I, Ouafik L, Garcia S, Mazieres J, Barlesi F and Mascaux C: Efficacy of immune 
checkpoint inhibitors in kras-mutant non-small cell lung cancer (nsclc). J Thorac Oncol 14(6): 1095-1101, 2019. PMID: 30738221. DOI: $10.1016 /$ j.jtho.2019.01.011

19 Dong ZY, Zhong WZ, Zhang XC, Su J, Xie Z, Liu SY, Tu HY, Chen HJ, Sun YL, Zhou Q, Yang JJ, Yang XN, Lin JX, Yan HH, Zhai HR, Yan LX, Liao RQ, Wu SP and Wu YL: Potential predictive value of tp53 and kras mutation status for response to pd-1 blockade immunotherapy in lung adenocarcinoma. Clin Cancer Res 23(12): 3012-3024, 2017. PMID: 28039262. DOI: 10.1158/1078-0432.CCR-16-2554

20 Skoulidis F, Byers LA, Diao L, Papadimitrakopoulou VA, Tong P, Izzo J, Behrens C, Kadara H, Parra ER, Canales JR, Zhang J, Giri U, Gudikote J, Cortez MA, Yang C, Fan Y, Peyton M, Girard L, Coombes KR, Toniatti C, Heffernan TP, Choi M, Frampton GM, Miller V, Weinstein JN, Herbst RS, Wong KK, Zhang J, Sharma P, Mills GB, Hong WK, Minna JD, Allison JP, Futreal A, Wang J, Wistuba, II and Heymach JV: Co-occurring genomic alterations define major subsets of kras-mutant lung adenocarcinoma with distinct biology, immune profiles, and therapeutic vulnerabilities. Cancer Discov 5(8): 860-877, 2015. PMID: 26069186. DOI: 10.1158/2159-8290.CD-14-1236

21 Schabath MB, Welsh EA, Fulp WJ, Chen L, Teer JK, Thompson ZJ, Engel BE, Xie M, Berglund AE, Creelan BC, Antonia SJ, Gray JE, Eschrich SA, Chen DT, Cress WD, Haura EB and Beg AA: Differential association of stk11 and tp53 with kras mutation-associated gene expression, proliferation and immune surveillance in lung adenocarcinoma. Oncogene 35(24): 32093216, 2016. PMID: 26477306. DOI: 10.1038/onc.2015.375

22 Eisenhauer EA, Therasse P, Bogaerts J, Schwartz LH, Sargent D, Ford R, Dancey J, Arbuck S, Gwyther S, Mooney M, Rubinstein L, Shankar L, Dodd L, Kaplan R, Lacombe D and Verweij J: New response evaluation criteria in solid tumours: Revised recist guideline (version 1.1). Eur J Cancer 45(2): 228247, 2009. PMID: 19097774. DOI: 10.1016/j.ejca.2008.10.026

23 Garrido P, Olmedo ME, Gomez A, Paz Ares L, Lopez-Rios F, RosaRosa JM and Palacios J: Treating kras-mutant nsclc: Latest evidence and clinical consequences. Ther Adv Med Oncol 9(9): 589-597, 2017. PMID: 29081842 . DOI: $10.1177 / 1758834017719829$

24 Pecuchet N, Laurent-Puig P, Mansuet-Lupo A, Legras A, Alifano M, Pallier K, Didelot A, Gibault L, Danel C, Just PA, Riquet M, Le Pimpec-Barthes F, Damotte D, Fabre E and Blons H: Different prognostic impact of stk11 mutations in non-squamous non-small-cell lung cancer. Oncotarget 8(14): 23831-23840, 2017. PMID: 26625312. DOI: 10.18632/oncotarget.6379

25 Koyama S, Akbay EA, Li YY, Aref AR, Skoulidis F, Herter-Sprie GS, Buczkowski KA, Liu Y, Awad MM, Denning WL, Diao L, Wang J, Parra-Cuentas ER, Wistuba, II, Soucheray M, Thai T, Asahina H, Kitajima S, Altabef A, Cavanaugh JD, Rhee K, Gao P, Zhang H, Fecci PE, Shimamura T, Hellmann MD, Heymach JV, Hodi FS, Freeman GJ, Barbie DA, Dranoff G, Hammerman PS and Wong KK: Stk11/lkb1 deficiency promotes neutrophil recruitment and proinflammatory cytokine production to suppress t-cell activity in the lung tumor microenvironment. Cancer Res 76(5): 999-1008, 2016. PMID: 26833127. DOI: 10.1158/0008-5472.CAN-15-1439
26 Bange E, Marmarelis ME, Hwang W-T, Yang Y-X, Thompson JC, Rosenbaum J, Bauml JM, Ciunci C, Alley EW, Cohen RB, Langer CJ, Carpenter E and Aggarwal C: Impact of kras and tp53 comutations on outcomes after first-line systemic therapy among patients with stk11-mutated advanced non-small-cell lung cancer. JCO Precis Oncol 3: 1-11, 2019. DOI: 10.1200/ po.18.00326

27 Del Re M, Rofi E, Restante G, Crucitta S, Arrigoni E, Fogli S, Di Maio M, Petrini I and Danesi R: Implications of kras mutations in acquired resistance to treatment in nsclc. Oncotarget 9(5): 6630-6643, 2018. PMID: 29464099. DOI: 10.18632 /oncotarget 23553

28 Mazieres J, Drilon A, Lusque A, Mhanna L, Cortot AB, Mezquita L, Thai AA, Mascaux C, Couraud S, Veillon R, Van Den Heuvel M, Neal J, Peled N, Fruh M, Ng TL, Gounant V, Popat S, Diebold J, Sabari J, Zhu VW, Rothschild SI, Bironzo P, Martinez A, Curioni-Fontecedro A, Rosell R, Lattuca-Truc M, Wiesweg M, Besse B, Solomon B, Barlesi F, Schouten RD, Wakelee H, Camidge DR, Zalcman G, Novello S, Ou SI, Milia $\mathrm{J}$ and Gautschi O: Immune checkpoint inhibitors for patients with advanced lung cancer and oncogenic driver alterations: Results from the immunotarget registry. Ann Oncol, 2019. PMID: 31125062. DOI: 10.1093/annonc/mdz167

29 Mazieres J, Drilon AE, Mhanna L, Milia J, Lusque A, Cortot AB, Mezquita L, Thai A, Couraud S, Veillon R, Mascaux C, Schouten R, Neal JW, Ng TL, Frueh M, Peled N, Gounant V, Popat S, Zhu VW and Gautschi O: Efficacy of immune-checkpoint inhibitors (ICI) in non-small cell lung cancer (nsclc) patients harboring activating molecular alterations (immunotarget). J Clin Oncol 36(15_suppl): 9010-9010, 2018. DOI: 10.1200/JCO.2018. 36.15_suppl.9010

30 Fakih M, O'Neil B, Price TJ, Falchook GS, Desai J, Kuo J, Govindan R, Rasmussen E, Morrow PKH, Ngang J, Henary HA and Hong DS: Phase 1 study evaluating the safety, tolerability, pharmacokinetics (PK), and efficacy of AMG 510, a novel small molecule KRASG12C inhibitor, in advanced solid tumors. J Clin Oncol 37(15_suppl): 3003-3003, 2019. DOI: 10.1200/JCO. 2019.37.15_suppl.3003
Received June 18, 2019

Revised July 17, 2019

Accepted July 29, 2019 